describo chemical syntheses of porphyrins and there would have been little point in trying to cover this topic here. A considerable amount of information, however, has been compressod into these two chapters. Spectral properties, co-ordination with motals and other ligands, redox equilibria, and acid-base proporties aro all included. $R$. Hill has contributed an eminently readable account of the ehlorophyll field; the ompirioul nomenclature is carefully explained and, as expocted, the spectral and photochemical properties of chlorophyll feature prominontly. Section $A$ concludes with a very brief account of bile pigments by C. H. Gray; chemical facts aro kopt to a minimum, but there are some interesting sidelights on the rolation between bile pigments and jaundice. Part $B$ opens with an extensive account of isoprenoid compounds by A. J. Haagen-Smit and C. C. Nimmo. Starting from hemiterpenoids, the authors progress by stages to polyterpenoids such as rubber. Inescapably, owing to tho biosynthetic versatility of nature and the nomenclatural inolegances of terpene chomists, the journey includes a vast numbor of names and formulæ. Tho authors have made a commendable offort to simplify the reader's task by stressing structural and stereochomical rolationships. It should be mentioned that, on p. $125, \alpha$-pinene is incorrectly stated to have a fused four- and five-membered ring system. The succeeding chapter on vitamin A by J. G. Baxter, although it includes a lot of material, has an annoying feature. The toxt cites two types of references; one gives author's name and date but no journal reference, while the othor gives full literature details. For the amount of space involvod, all the references could have beon given in full. The next two chaptors, by R. S. Harris, deal with vitamins $\mathrm{E}$ and $\mathrm{K}$. They are so short as to be almost useless except as literature sources. Surprisingly, quinones including ubiquinones qualify for separate treatment by R. A. Morton. It would have been moro setisfactory if the chapters on vitamin $K$ and quinones had been combined. Section $C$ consists of one chapter by T. A. Geissman on phenolic plant constituents. This deals with the broad range of flavonoid compounds, tannins, and compounds bused on $a \mathrm{C}_{B}-\mathrm{C}_{3}$ phenylpropano unit. Classification reflects biosynthesis so far as is possible, and this serves as a unifying feature of the chaptor. It is unfortunate that naturally occurring polyacetylenes were not included in this volume.

Volume 10 is entirely devoted to storoidal compounds and opens with a chapter by D. Kritchevsky on sterols. After brief introductory sections on the structure and conformation of steroids in general, there is a very condensed account of cholesterol and related compounds. The biochemist may be surprised to find vitamin D dismissed en passant in less than a pago. On p. 16, agnosterol is incorrectly stated to be more highly saturated than lanostorol. The essential featuros and possible biochemical functions of bile salts are described in a short chapter by G. A. D. Haslewood. In the remaining four chapters, steroids receive more liberal treatment. G. I. Fujimoto and R. W. Ledeen set forth the chief aspocts of the chemistry of androgens and mention important synthetic analogues with differing relativo androgenic and anabolic activitios. The chemistry of cestrogens is described by P. A. Katzmann and W. H. Elliott, and reactions of the four rings are treated separately at some length. Methods of soparation, isolation and determination are also mentioned. Tho longost chapter, by H. J. Ringold and A. Bowers, is devoted to adrenal hormones. A discussion of the reactions of the side-chain and functional groups of cortisone and hydrocortisone loads naturally to an account of the immonse effort, which has boen directed to the synthesis of these hormones and many structural analogues. Although desoxyeorticosterone and aldosterono recoivo soparate mention, the authors rightly stress that the rigid clnasification of corticosteroids into glucocorticoids and mineralocorticoids is unrealistic; indeed, the relationship between structure and biological activity is repeatedly emphasizod. Finally, progestational hormones are described by J. A. Zdoric, and the treatment resembles that in the previous chapter. A great doal of information relating to biological activity is offectively summarized in tables.

Roading these two volumes, I was surprised at the variation in the ratio of the number of literature references to number of pages of text. This ranged from 0.6 to 8.8 , and the highost ratios occurred in the shortest chapters. Clearly, a dull uniformity would be deplorable, but a high ratio is not suitable for a text-book, since the reader has to find most of his information elsewhere, while a low ratio could result from either verbosity or the regurgitntion of reviews already published.

D. 'T. ELMORE

\section{WORKED EXAMPLES IN ELECTRICAL ENGINEERING}

\section{Examples in Advanced Electrical Engineering}

By Prof. J. F. W. Bell. (Electrical Engineering Serios.) Pp. 199. (London: The English Universities Press, Ltd., 1962.) 18s. not.

ROOKS containing solutions to examination questions $B$ are always popular with students, who hope, with their aid, to make themselves proficient at answering questions within the strict time limits of an examination. The majority of such books confine themselves to the solution of numerical problems, but Examples in Advanced Electrical Engineering is one of the select fow in which a model answer is given to the whole question as set in the examination peper. Most of the questions are taken from recent Part III papers of the University of London B.Sc.(Eng.) examination. Prof. J. F. W. Bell is not afraid to include critical comment where, in his view, the question was too easy, too long or ambiguous in its wording.

Examiners are, however, not in an easy position in sotting papers. Excellent books, like the present one, must not be allowod to provide the student with a short cut to passing examinations without a propor understanding of the subject-matter bohind the questions. In their search for new questions which can be answered adoquately in half an hour, some artificiality is at times unavoidable and a little ambiguity also is sometimes preferable to tho use of more words, which the student has to interpret before he can start answering the quostion. The student has one big advantage over the author of a book of model answors, in that his limitod knowledge usually eliminates most of the ambiguities from the answer he is able to give. In this respect, the brilliant student may be at somo disadvantage comparod with those of average calibre, but examiners have little difficulty in spotting brilliance. However, this book shows cloarly the proper method of dealing with ambiguities when these aro appreciated by the student. The student's interpretation of tho question with respect to the ambiguity should be clearly stated in his answer.

It is evident from a study of the model answers that few of these could bo given by the student within the time limits allowed. This is of small moment, since students are very oxport at abbreviation. Perhaps a more valid criticism would bo the lack of solutions by alternative mothods.

Alternative solutions would not only be of assistnnce to those students who were more familiar with the alternative method, but by having two or more solutions side by side the student could see the relative merits of different techniquos more easily and tho oducative value of the book would theroby be enhanced. The prico of the book, very moderate at prosent, might also be enhanced by this additional material. The author may well have had this in mind.
A. H. M. Arnold 